\title{
TMV-Cg Coat Protein stabilizes DELLA proteins and in turn negatively modulates salicylic acid-mediated defense pathway during Arabidopsis thaliana viral infection
}

\author{
Maria Cecilia Rodriguez ${ }^{1,2}$, Gabriela Conti ${ }^{1,2}$, Diego Zavallo ${ }^{1,2}$, Carlos Augusto Manacorda ${ }^{1}$ and Sebastian Asurmendi ${ }^{1,2^{*}}$
}

\begin{abstract}
Background: Plant viral infections disturb defense regulatory networks during tissue invasion. Emerging evidence demonstrates that a significant proportion of these alterations are mediated by hormone imbalances. Although the DELLA proteins have been reported to be central players in hormone cross-talk, their role in the modulation of hormone signaling during virus infections remains unknown.

Results: This work revealed that TMV-Cg coat protein (CgCP) suppresses the salicylic acid (SA) signaling pathway without altering defense hormone SA or jasmonic acid (JA) levels in Arabidopsis thaliana. Furthermore, it was observed that the expression of CgCP reduces plant growth and delays the timing of floral transition. Quantitative RT-qPCR analysis of DELLA target genes showed that CgCP alters relative expression of several target genes, indicating that the DELLA proteins mediate transcriptional changes produced by CgCP expression. Analyses by fluorescence confocal microscopy showed that CgCP stabilizes DELLA proteins accumulation in the presence of gibberellic acid (GA) and that the DELLA proteins are also stabilized during TMV-Cg virus infections. Moreover, DELLA proteins negatively modulated defense transcript profiles during TMV-Cg infection. As a result, TMV-Cg accumulation was significantly reduced in the quadruple-DELLA mutant Arabidopsis plants compared to wild type plants.

Conclusions: Taken together, these results demonstrate that $\mathrm{CgCP}$ negatively regulates the salicylic acid-mediated defense pathway by stabilizing the DELLA proteins during Arabidopsis thaliana viral infection, suggesting that CgCP alters the stability of DELLAs as a mechanism of negative modulation of antiviral defense responses.
\end{abstract}

Keywords: TMV-Cg, Coat protein, DELLA proteins, SA signaling, Defense response

\section{Background}

During the co-evolutionary process established between plants and virus pathogens, plant viruses have evolved various means of altering host components to efficiently infect plants. Emerging evidence has shown that viruses disturb the defense regulatory pathways of plants by producing hormonal imbalances [1]. The role of hormones in the induction of disease had been suggested in earlier reports; however, these studies have not characterized the factors involved in hormonal imbalances [2]. Recently,

\footnotetext{
* Correspondence: asurmendi.sebastian@inta.gob.ar

${ }^{1}$ Instituto de Biotecnología, CICVyA-INTA, 1686 Hurlingham, Buenos Aires, Argentina

${ }^{2}$ Consejo Nacional de Investigaciones Científicas y Técnicas (CONICET), Hurlingham, Buenos Aires, Argentina
}

some virus proteins have been shown to alter either or both the localization and activity of host components, which might influence the hormonal balance during compatible interactions $[3,4]$. For example, Rice dwarf virus (RDV) P2 viral protein modifies a factor involved in the biosynthesis of gibberelic acid (GA) [3] and consequently there is a diminished accumulation of GA. The $\mathrm{C} 2$ protein of Geminivirus interferes with a regulatory component of the ubiquitination pathway [4], which is involved in the regulation of many hormonal responses [5]. Also, the TMV replicase protein was found to disrupt the localization of the auxin response regulator indole acetic acid IAA26/PAP1, thus altering the expression of auxin regulated genes [6,7]. More recently, it was observed that 
TMV-Cg alters the function of a transcription factor involved in the balance of abscisic acid/ethylene signaling pathway [8].

Tobamoviruses have a single stranded RNA genome that encodes four well-characterized proteins: two proteins responsible for RNA-dependent RNA replication; another involved in cell to cell movement and, finally, a coat protein (CP) $[9,10]$. Tobamovirus CPs are mainly associated with a structural function during virion assembly. However CP is also involved in several other aspects of virus infection [11]. For example, Tobacco mosaic virus CP (TMV CP) is required for systemic movement to distant plant tissues [12] and is found in viral replication complexes, suggesting that TMV CP may be required for efficient virus replication $[13,14]$. Furthermore, TMV CP greatly affects the development of symptoms in viral infection [15] and confers heterologous interference to other virus [16].

Transgenic plants that accumulate TMV CP show a marked resistance towards the virus with a consequent delay in symptoms appearance [17]. Such phenomenon is known as coat protein-mediated resistance (CP-MR). $\mathrm{CP}$ transgenic plants inoculated with TMV-RNA overcome this resistance mechanism; which led Beachy to propose that CP blocks an early infection step [10]. Carr et al. [18] investigated a possible role of pathogenesis related proteins ( $\mathrm{PR}$ proteins) in CP-MR but could not obtain positive evidence. In contrast, recent results obtained by our group showed that transgenic tobacco plants expressing TMV CP accumulate reduced mRNA levels of some salicylic acid (SA) responsive genes such as pathogenesis-related (PR-1) and RDR1(RNA-dependent RNA polymerase 1) when compared to WT (non-transgenic wild type) plants [19].

In many compatible plant-virus interactions, SA reduces viral replication and restricts cell-to-cell movement and systemic movement [20-22]. Studies in Arabidopsis leaves inoculated with RNA viruses showed that at least one third of the common sets of genes induced by viruses are associated with plant defense and stress responses [23]. Most importantly, the induction of many of these genes is compromised in SA-signaling mutants. This finding demonstrates that SA is involved in the viral-induced signaling that occurs during compatible virus interactions [24] and suggests that plant viruses have evolved strategies to evade the SA-induced defense during compatible interactions. Several studies have demonstrated that viral proteins can suppress SA signaling $[25,26]$, reinforcing the evasion hypothesis. The DELLA proteins are negative regulators of growth and in the presence of GA are degraded through the ubiquitin-proteasome pathway [27]. These proteins may also play a role as integrative hub in hormone cross-talk [28]. Furthermore, they are also known to promote susceptibility to biotrophic bacterial pathogens by repressing SA defense response in Arabidopsis thaliana [29]. Recently, several reports have shown that viruses alter hormone biosynthesis and signaling [1]. However, the role of DELLA proteins in the modulation of signaling events during virus infection has not been characterized yet.

To extend the analysis of the role of Tobamovirus coat proteins during compatible virus interactions, we conducted studies to determine if CP from TMV-Cg is capable of modulating defense responses in Arabidopsis thaliana. TMV-Cg is a Tobamovirus that infects Arabidopsis [30]. For this experiment, we used transgenic plants expressing $\mathrm{CgCP}$ under an inducible promoter [31]. The transgenic expression of CgCP stabilized DELLAs proteins and suppressed the expression of a set of SA-responsive genes. In the present study, we determined the role of DELLAs proteins in the modulation of signaling events during TMV-Cg infection. We demonstrated that during TMV-Cg infection CgCP stabilizes DELLAs proteins and this stabilization results in the modulation of SA-defense signaling pathway.

\section{Results}

$\mathrm{CgCP}$ expression downregulates the expression of SA-responsive genes in Arabidopsis but does not alter SA or JA levels

To study the role of CgCP expression during viral defense signaling responses, we employed an Arabidopsis transgenic line (CP\#72) harboring the $\mathrm{CgCP}$ gene that is regulated by an inducible promoter [31]. This chemically inducible gene expression system employs methoxyfenozide (MOF) as the inducer [31,32]. The CP\#72 transgenic plants were grown to stage 1.08 [33] (approximately 20 days after germination) to establish the CgCP expression level. Then, the plants were treated with MOF and samples were collected at different time points after induction. RT-qPCR was used to compare the level of the CgCP mRNA from CP\#72 with the level of a constitutive transgenic line expressing TMV-Cg CP under the Cauliflower mosaic virus (CaMV) $35 \mathrm{~S}$ promoter (CP\#71). The $\mathrm{CgCP}$ accumulation level was also determined in the WTCol-0 (non-transgenic) TMV-Cg infected plants. Twentyfour hours post $\mathrm{CgCP}$ induction, the inducible line (CP\#72) showed higher levels of $\mathrm{CP}$ transcripts than the line that constitutively expresses $\mathrm{CgCP}(\mathrm{CP} 71)$ (Figure 1). The maximum level of accumulation was reached at $48 \mathrm{~h}$ and was maintained at $72 \mathrm{~h}$ post-induction (Figure 1). Nevertheless, the level was lower than the level reached 7 days post infection (dpi) in the TMV-Cg infected plants (Figure 1). The temporal pattern of $\mathrm{CgCP}$ accumulation reported here was similar to that reported by Koo et al. [31].

In a previous work, we demonstrated that $N$. tabacum transgenic plants expressing TMV CP accumulate reduced 


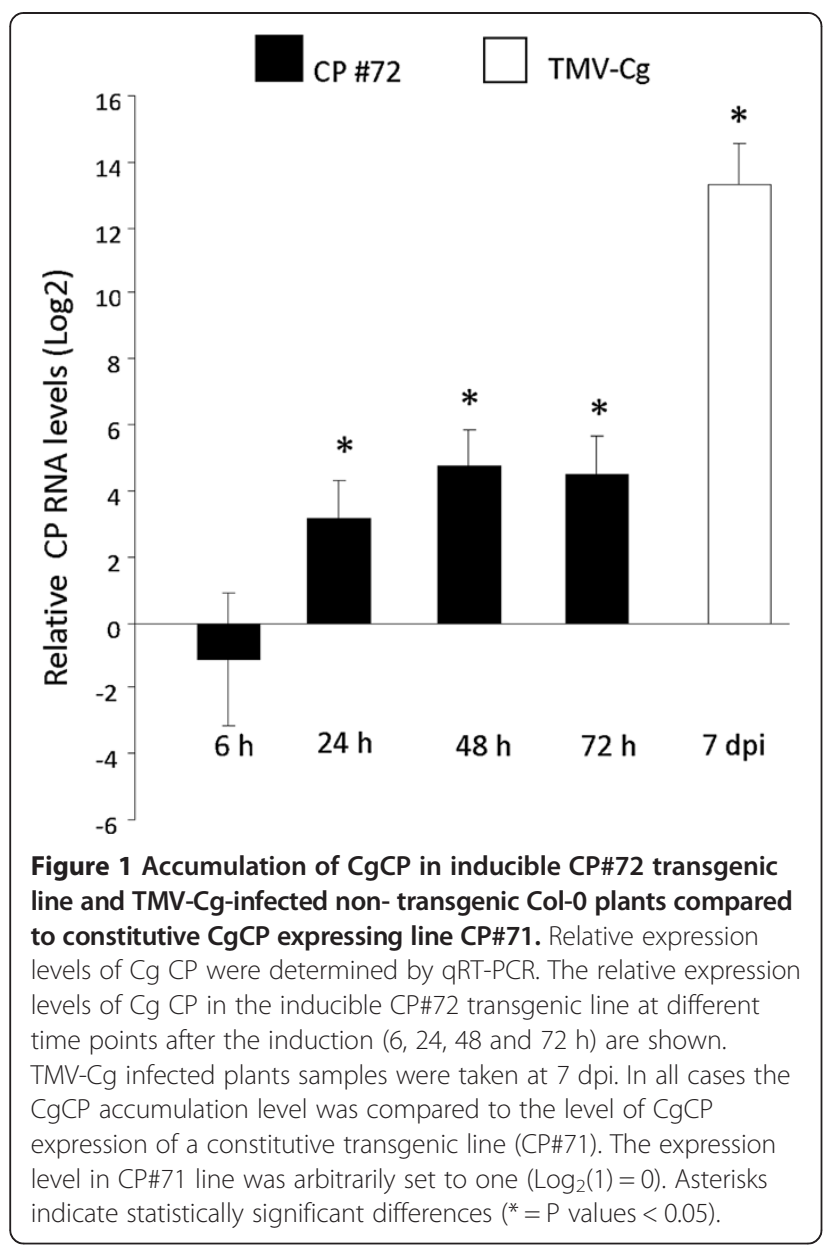

levels of $P R-1$ and $R D R-1$ transcripts [19]. Based on those findings, we selected a group of SA-responsive genes involved in antiviral defense signaling in order to quantify their transcript levels in the CP\#72 transgenic line: RDR1; $A O X 1 A$ and WRKY7O. RDR1 is a component of RNA silencing machinery [34]. AOX1A is the terminal oxidase of the cyanide-resistant alternative respiratory pathway in plants, which is also implicated in virus resistance [21]. Finally, WRKY70 was chosen based on its well-known regulatory role in SA signaling pathway [35].

A reduction of RDR1 and WRKY7O mRNA levels was observed in MOF-treated CP\#72 plants compared to water-treated CP \#72 plants at 48 and $72 \mathrm{~h}$ post induction, while a reduction of $A O X 1 A$ mRNA levels was detected only $72 \mathrm{~h}$ post $\mathrm{CgCP}$ induction (Figure $2 \mathrm{~A}$ ). In parallel, we quantified the same set of genes in the $\mathrm{CP} 771$ independent transgenic line (Figure 2B). RDR1 and WRKY70 also showed reduced expression levels in this independent transgenic line when compared to the nontransgenic plants. However, AOX1A remained unaltered in the $\mathrm{CP} \# 71$ transgenic line.

An additional control experiment was performed to exclude that the transcriptional changes observed in the
$\mathrm{CP} \# 72$ transgenic lines were because of the MOF treatment. We determined the level of expression of these transcripts in WT- Col-0 plants treated either with water or MOF ( $48 \mathrm{~h}$ after MOF). The results from this experiment showed no statistically significant differences between both treatments, confirming that all the expression changes are exclusively due to $\mathrm{CgCP}$ expression (Additional file 1).

Next, we analyzed the expression levels of WRKY70, $A O X 1 A$ and $R D R 1$ in response to $\mathrm{CgCP}$ induction under $\mathrm{SA}$ hormone treatment (Figure 2C). For this purpose, $\mathrm{CP} 72$ transgenic plants were initially treated with MOF or water and subsequently (48 $\mathrm{h}$ later) sprayed with $0.5 \mathrm{mM} \mathrm{SA}$ or water. Gene expression levels were analyzed $24 \mathrm{~h}$ after hormone treatment using as reference untreated $\mathrm{CP} \# 72$ plants (no MOF and no SA) (CP\#72 control). As expected, the levels of WRKY70, AOX1A and $R D R 1$ were increased in the control plants (exposed to water) after SA treatment $(\mathrm{CP} \# 72(-)+\mathrm{SA})$. However, the $\mathrm{SA}$ treatment did not increase gene expression in MOF -induced $\mathrm{CP} \# 72$ plants $(\mathrm{CP} \# 72(\mathrm{MOF})+\mathrm{SA})$, when compared to water-treated $\mathrm{CP} \# 72$ control plants (Figure 2C). Thus, these results indicate that $\mathrm{CgCP}$ negatively modulates the WRKY70, AOX1A and RDR1 transcript levels after SA treatment.

As $\mathrm{CgCP}$ altered the expression of genes involved in SA signaling, we next quantified the levels of SA and jasmonic acid (JA) in CP\#72 transgenic plants and WTCol-0 treated with MOF. JA was selected because of its antagonistic role to SA. After MOF treatment, no statistical differences were observed in SA or in JA levels between $\mathrm{CP} \# 72$ and WT plants throughout the study, not even at $0 \mathrm{~h}$ (non-induced plants) (Figure 2D). This finding is in agreement with our previous results in TMV-infected Nicotiana tabacum [19]. Therefore, these experiments demonstrate that $\mathrm{CgCP}$ modulates the SA signaling without altering SA or JA basal levels.

\section{$\mathrm{CgCP}$ expression reduces plant growth and delays the timing of floral transition}

Recent evidence showed that plant viruses can interfere with hormone synthesis and signaling and, as a result, plant development is altered [1]. To study whether CgCP alters Arabidopsis thaliana normal development, we analyzed the phenotype of $\mathrm{CgCP}$ transgenic plants in detail.

The MOF-induced CP\#72 plants showed a reduction in plant height (Figure 3A) and a delay in flowering time (Figure 3B) when compared to $\mathrm{CP} \# 72$ plants that were treated with water. As another control, non-transgenic Col-0 plants were treated with MOF. No statistical differences were detected when these controls were compared with the $\mathrm{CP} \# 72$ plants that were treated with water. Thus, the expression of $\mathrm{CgCP}$ was the main cause 

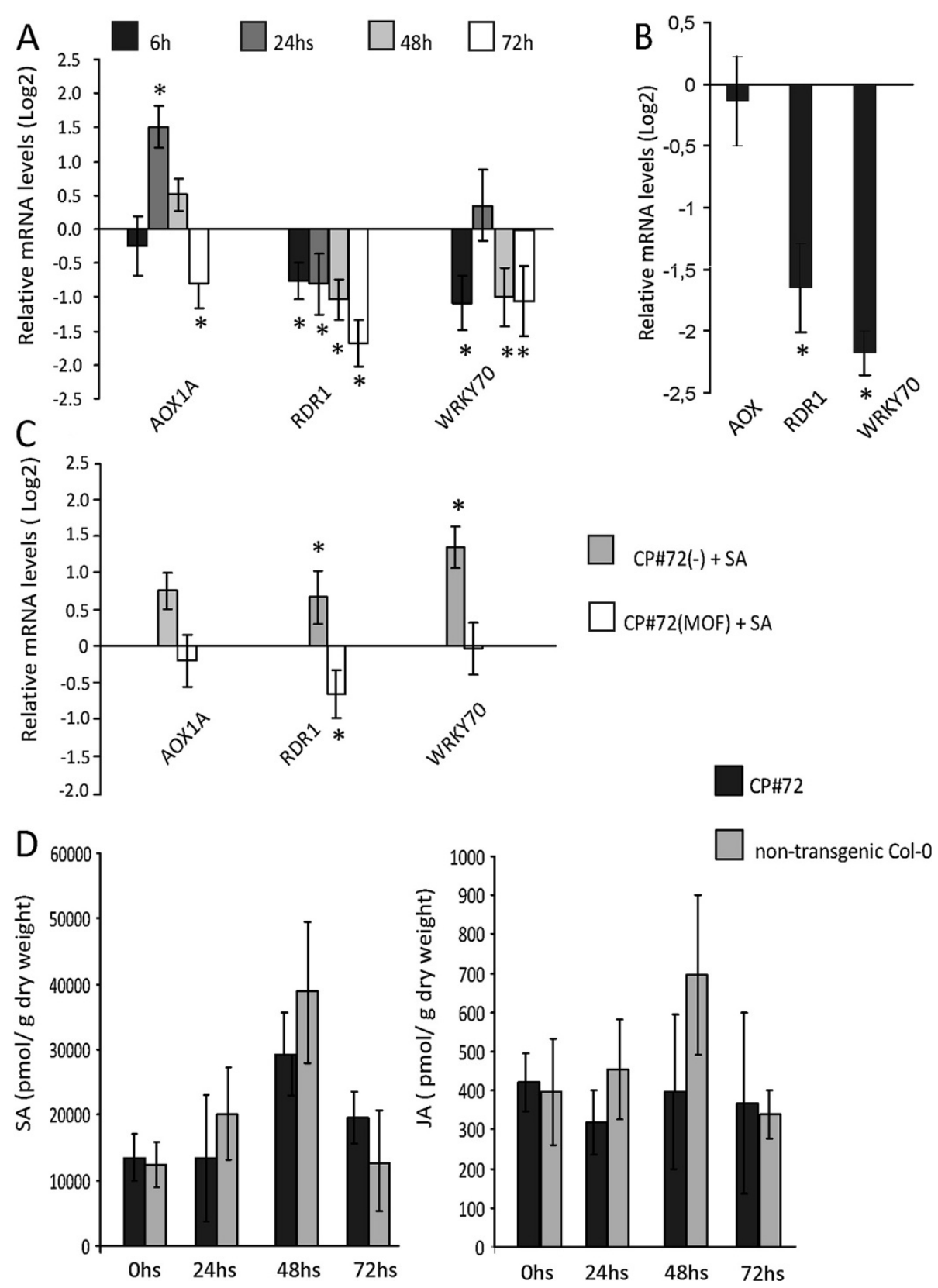

Figure 2 CgCP expression downregulates transcriptional levels of SA-responsive genes, but it does not alter endogenous SA or JA levels. A) Relative mRNA levels of AOX1A, RDR1 and WRKY70 genes after CgCP induction in CP\#72(MOF) plants (MOF treated) over a $72 \mathrm{~h}$ time course. Non-induced CP\#72(-) (water treated) were used as reference controls and the expression level was arbitrarily set to one $\left(\log _{2}(1)=0\right)$. B) Relative mRNA levels in constitutively expressing CP \#71 line compared to WT Col-0 plants at 1.08 developmental stage. The expression level in WT line was arbitrarily set to one $\left(\log _{2}(1)=0\right)$. C) Relative mRNA levels in CP\#72 line after SA treatment. CP\#72(-) (water treated) or MOF-treated CP\#72 (MOF) plants at $48 \mathrm{~h}$ post induction were sprayed either with $0.5 \mathrm{mM} \mathrm{SA}(+\mathrm{SA})$ or water $(-)$. The expression levels were referenced to noninduced CP\#72(-) plants (water treated) and arbitrarily set to one $\left(\log _{2}(1)=0\right)$. A), B) and C) Relative transcript levels were determined by RT-qPCR. Data correspond to the mean \pm standard error of four biological replicates. Asterisks indicate statistically significant differences $\left({ }^{*}=\mathrm{P}\right.$ values $\left.<0.05\right)$. D) JA and SA accumulation level determined by HPLC in induced CP\#72 and non-transgenic Col-0 plants at 0, 24, 48 and $72 \mathrm{~h}$ post induction with MOF. Data at $0 \mathrm{~h}$ correspond to untreated plants. The means of four biological replicates $\pm \mathrm{SE}$ are shown.

of the delay in the height and timing of floral transition (Figure 3A, B and C). We also evaluated the phenotype of CP\#71 transgenic plants (Additional file 2). Similarly to that observed in $\mathrm{CP} \# 72$ transgenic plants treated with MOF, CP\#71 showed a reduction in plant height (Additional file 2) and a delay in flowering time (Additional file 2) when compared to non-transgenic Col-0 plants. These developmental changes had not been reported in 


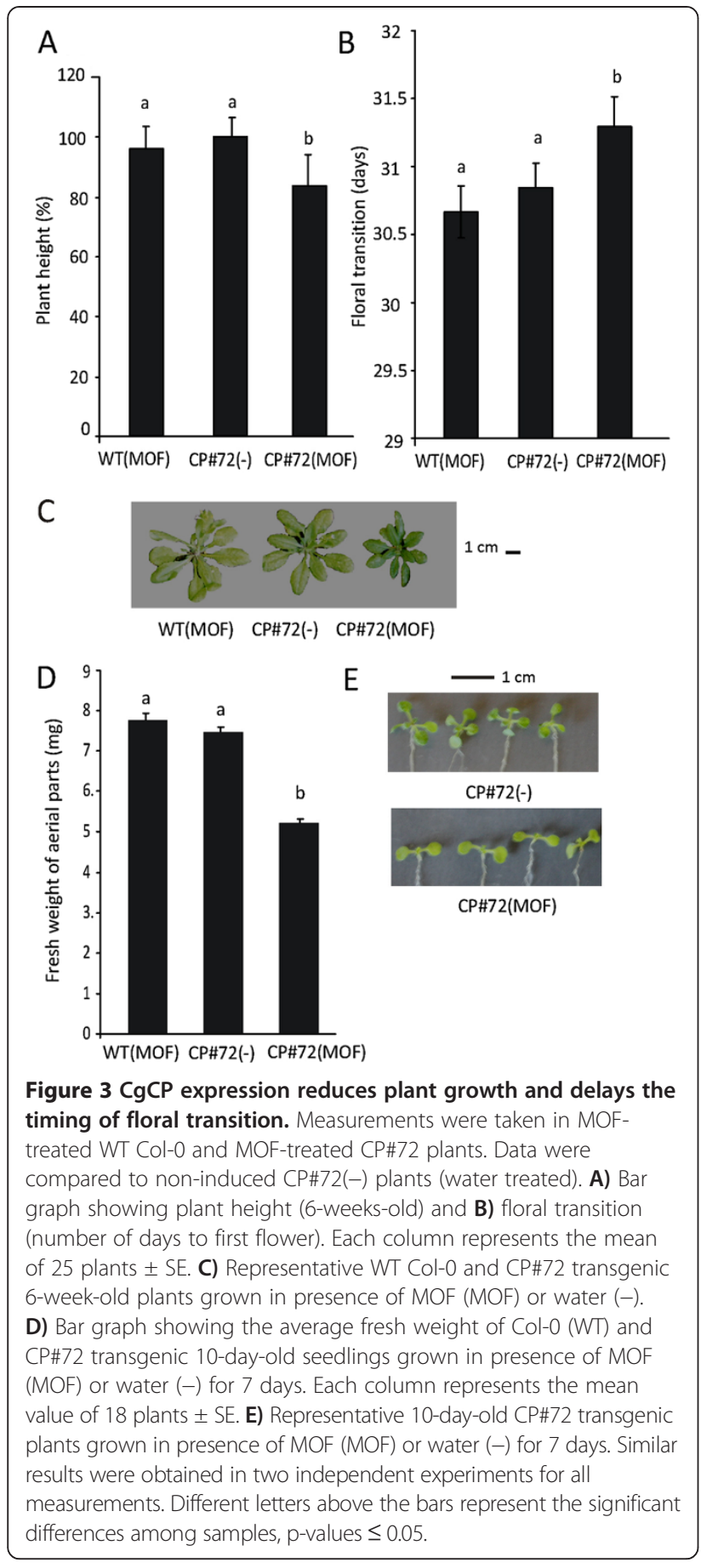

Koo et al.'s work (2004), maybe due to the differences in the used experimental procedures. In the experiments carried out by Koo et al. using the $\mathrm{CP} 72$ transgenic line, MOF treatment of the CP\#72 line was performed at a later developmental stage (five/six weeks of age), when inflorescences have already emerged [33]. For this reason, $\mathrm{CP}$ accumulation had no effect on the timing of floral transition. Accordingly, when we analyzed the seedling development, in $\mathrm{CP} \# 72$ transgenic line, we detected striking reductions of growth in the aerial parts of the MOFinduced $\mathrm{CP} \# 72$ transgenic line in comparison with the seedlings that were treated with water (Figures $3 \mathrm{D}$ and $\mathrm{E}$ ). For this analysis, we also used non-transgenic Col-0 seedling plants treated with $\mathrm{MOF}$ as controls (wild type plants, WT). As shown in Additional file 3, no differences were observed in the growth of MOF-treated WT Col-0 plants in comparison with water-treated non-transgenic Col-0 plants. Therefore, $\mathrm{CgCP}$ altered the normal development of Arabidopsis seedlings and adult plants but only when $\mathrm{CgCP}$ is expressed during the early stages of development. The effect of $\mathrm{CgCP}$ expression on development and hormone signaling pathways suggests that $\mathrm{CgCP}$ could be altering a fundamental component involved in the regulation of growth and hormone cross-talk. The DELLA proteins are central to both processes [28,36,37]; therefore, these proteins could play a role in the phenotypes observed during $\mathrm{CgCP}$ expression. Together, this data prompted us to analyze the role of DELLA proteins during $\mathrm{CgCP}$ expression.

\section{$\mathrm{CgCP}$ increases the expression of DELLA target genes and} stabilizes DELLA protein accumulation

To explore whether DELLAs play a role in the changes observed during $\mathrm{CgCP}$ expression, we analyzed the mRNA transcript levels of a set of DELLA-responsive genes (Zentella et al., 2007). UBIQUITIN- CONJUGATIN ENZYME 17 (UBC17), IQ-DOMAIN 22 (IQD22), GA INSENSITIVE DWARF1B (ATGID1b) and BASIC HELIX -LOOP HELIX 137 (bHLH137) are transcripts which are downregulated by GA and upregulated by DELLA protein stabilization in seedlings plants [38]. To study the transcript levels of this set of genes in rosette leaves, we quantified their expression in Arabidosis cv Ler quadruple-DELLA mutants (plants lacking four DELLA genes: RGA, GAI, RGL1, RGL2) [27] and also in Ler gai-1 mutants (gibberellin-insensitive plants due to GAI-constitutive stabilization) [39]. For this experiment, we collected rosette leaf tissue at 1.08 developmental stage. UBC17 and bHLH 137 transcript levels were statistically increased in the gai-1 plants compared to the nonmutant Ler plants (Additional file 4). On the other hand, $U B C 17, I Q D 22, A T G I D 1 b$, transcript levels were statistically reduced in the quadruple-DELLA mutants compared to the non-mutant Ler plants (Additional file 4).

Next, to determine the effect of $\mathrm{CgCP}$ on the transcription level of these genes, we quantified their transcription after CgCP induction. The MOF-induced CP\#72 (72 h after MOF exposure) plants accumulated higher levels of all the DELLA-target genes analyzed compared to the non-induced CP\#72 plants (Figure 3A). In addition, we evaluated the transcription level of two other DELLA regulated genes. The transcription levels of $\mathrm{Cu} / \mathrm{Zn}$ superoxide dismutases $(\mathrm{Cu} / \mathrm{Zn} \mathrm{SOD}), \mathrm{CSD} 1$ 
and CSD2, are positively modulated by DELLA proteins [36]. As shown in Figure 4A, both CSD1 and CSD2 transcript levels were upregulated by $\mathrm{CgCP}$; which suggests that the modulation of gene expression observed during $\mathrm{CgCP}$ expression might be regulated by DELLA proteins.

To determine whether the DELLA proteins are stabilized by $\mathrm{CgCP}$ expression, we analyzed protein accumulation after $\mathrm{CgCP}$ induction. For this purpose, we crossed a transgenic line expressing RGA, one of the five DELLA proteins, fused to GFP (pRGA::GFP-RGA) [40] with CP\#72 line obtaining CP\#72/pRGA::GFP-RGA. By using the homozygous sibling carrying both transgenes, we evaluated the levels of RGA-GFP in MOF- or watertreated seedlings in the presence of gibberellic acid $\left(\mathrm{GA}_{3}\right)(10 \mu \mathrm{M})$. RGA-GFP can be easily detected by fluorescence confocal microscopy at seedling stages [29]. As expected, RGA-GFP was degraded by GA treatment (Figure 4B) in the non-induced CP\#72/pRGA::GFP-RGA seedlings. However, $\mathrm{CgCP}$ expression reduced GAmediated degradation of RGA-GFP in Arabidopsis seedlings (Figure 4B).

With the aim of quantify the amount of GFP-RGA protein that was accumulated in the nuclei of Arabidopsis cells, the GFP-RGA fluorescence intensity of twenty random nuclei from five different plants for each treatment were analyzed using the ImageJ Software (for more detail, see Methods). No statistically significant differences were detected when GFP-RGA fluorescence was compared between CP\#72/RGA::GFP-RGA plants treated with MOF and CP\#72/RGA::GFP-RGA plants treated with water, prior the addition of $\mathrm{GA}_{3}$. After addition of $\mathrm{GA}_{3}$, GFP-RGA fluorescence was significantly reduced in nuclei of CP\#72/RGA::GFP-RGA transgenic plants treated with water (Figure $4 \mathrm{C}$ and Additional file 5). In contrast in CP\#72/RGA::GFP-RGA MOF-treated plants, the GFPRGA fluorescence was not reduced after the addition of $\mathrm{GA}_{3}$. $(10 \mu \mathrm{M}$ ) (Figure $4 \mathrm{C}$ and Additional file 5). Taken together, these experiments demonstrate that $\mathrm{CgCP}$ stabilizes DELLA proteins and, as a consequence, alters gene expression profiles.

\section{$\mathrm{CgCP}$ suppresses a set of defense genes that are regulated by DELLA proteins}

CgCP expression downregulated a set of SA-responsive genes (WRKY70, AOX1A and RDR1) and also stabilized the accumulation of DELLA proteins. Hence, we analyzed the expression levels of these transcripts in quadruple-DELLA and gai-1 mutants and, as expected, found that WRKY70, $A O X 1 A$ and $R D R 1$ were upregulated in the quadruple-DELLA mutants but downregulated in the gai-1 mutants. Wild type Arabidopsis Ler plants were used as reference controls for these experiments (Figure $5 \mathrm{~A}$ ). The regulation of RDR1 by DELLA

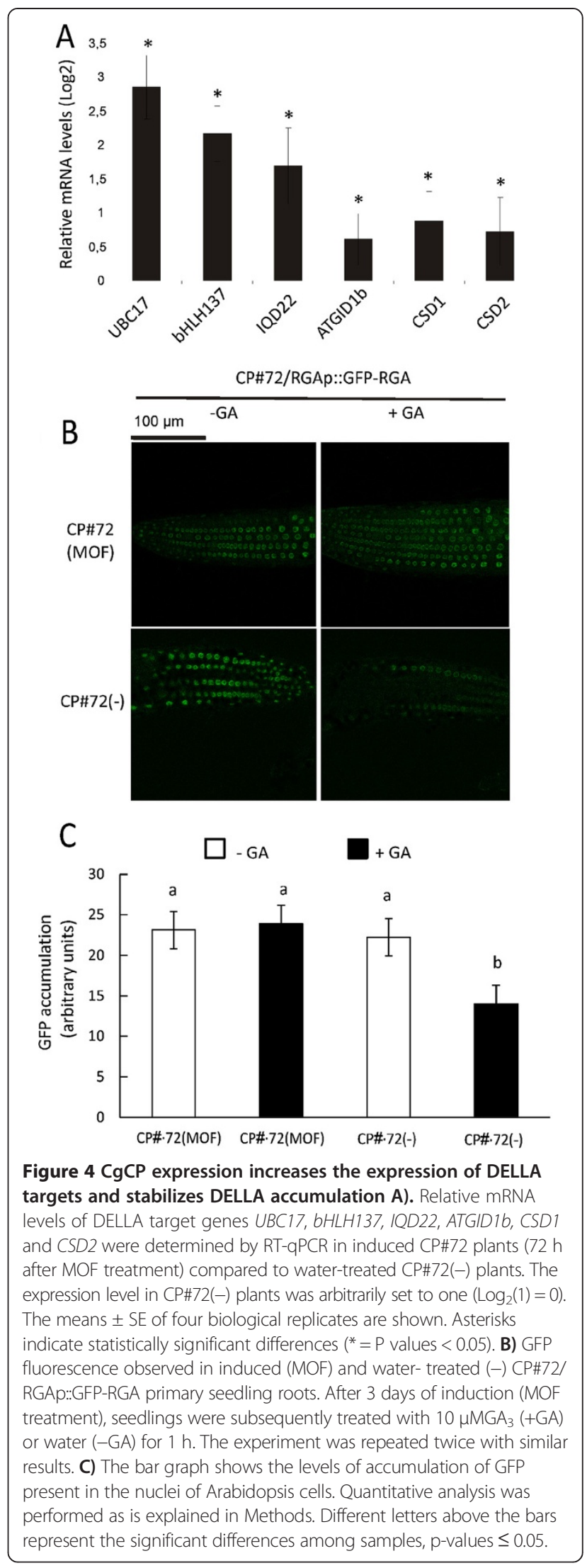




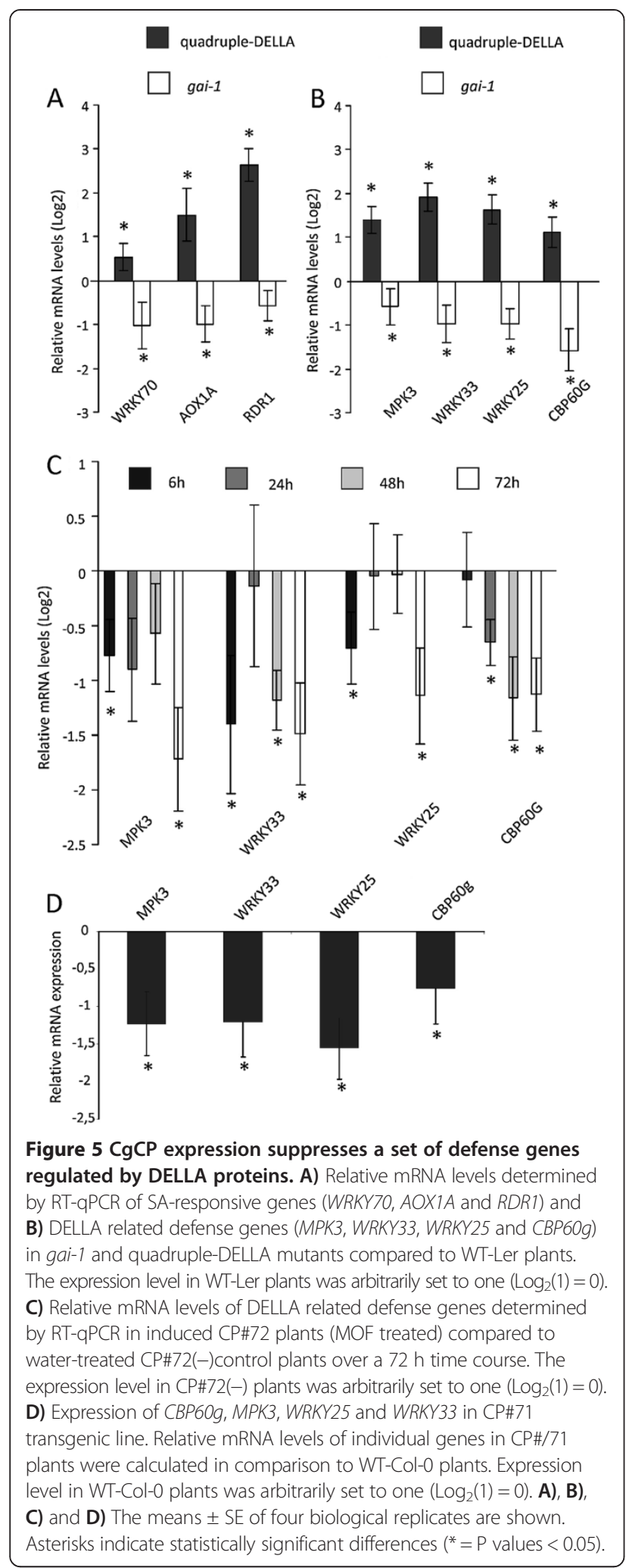

proteins is particularly interesting since this gene is essential for maintaining basal resistance to several RNA viruses including TMV-Cg [34].
SA is known to induce multiple virus resistance mechanisms [41,42] and $R D R 1$ is only one of the components involved in this mechanism. We proceeded to determine whether the DELLA protein stabilization by CgCP induction alters the expression of other important genes involved in SA-induced resistance. For this purpose, we included a larger set of candidates. The selection was based on the analysis of a microarray study performed between Arabidopsis gai-1 mutants and non- mutant (WT) plants treated with flg22 (GEO accession: GSE17464). Data were gathered from Genevestigator data base [43] (Additional file 6). This new set of candidate genes, which are involved in SA biosynthesis, innate immune signaling and stress response, showed reduced expression levels in the gai-1 mutant plants after flg22 (gai-1 + flg22) treatment compared to the non-mutant plants treated with flg22 (WT + flg22) (Additional file 6). CBP60G encodes a calmodulin binding protein that plays a role in SA accumulation and SA signaling [44]; MPK3 encodes a MAPKs activated by pathogen infections [45]; WRKY25 and WRKY33 respond to stress and increase expression after SA treatment $[46,47]$. By RT-qPCR, the transcription levels of these defense genes were quantified in the quadruple-DELLA mutants as well as in gai-1 mutants and these levels were compared to those of the WT-Ler control plants (Figure 5B). A higher level of expression of all these genes was detected in the quadruple-DELLA mutants compared to that of the WT-Ler plants. Instead, the gai-1 mutants showed reduced levels of these transcripts.

Next, we studied the expression of these genes in either MOF-induced or water-treated $\mathrm{CP} \# 72$ plants at 6 , 24, 48 and $72 \mathrm{~h}$ after CgCP induction (Figure 5C). Again, reduced expression levels were observed for all four genes in the CP\#72 plants after MOF treatment when compared to the $\mathrm{CP} \# 72$ plants treated with water. A similar downregulation of this set of genes was observed in a CP\#71 independent transgenic line that constitutively expresses $\mathrm{CgCP}$ when compared to the nontransgenic Col-0 plants (Figure 5D). Taken together, the expression profiles observed after CgCP expression are similar to those observed in the gai-1 mutants and opposed to the DELLA-quadruple mutants. Thus, these findings strongly suggest that $\mathrm{CgCP}$ expression is attenuating the expression of defense genes through the stabilization of DELLA proteins.

\section{TMV-Cg infection stabilizes DELLA protein accumulation}

Based on the results obtained, we decided to determine whether the CgCP effect on DELLA stabilization is also produced during TMV-Cg infection. For this experiment, Nicotiana benthamiana plants were inoculated with TMV-Cg virus or buffer (mock-inoculated). Later on (6 days), upper leaves plants were agroinfiltrated with YFP-GAI-expression construct [48]. N. benthamiana 
was selected because this plant allows a good expression of YFP-GAI fusion and easy detection using a fluorescence microscope [4]. Three days post-agroinfiltration, YFP-GAI accumulation was detected predominantly in nuclei of both TMV-Cg-infected $N$. benthamiana plants and virus mock-inoculated plants (see Figure 6A inset). Leaf explant of both set of plants were treated with $\mathrm{GA}_{3}$ $(100 \mu \mathrm{M})$ solution for an hour and were subsequently observed on a fluorescent microscope. As expected, the fluorescence decreased after GA treatment in the mockinoculated plants. A reduction of YFP-GAI fluorescence was also observed in the TMV-Cg infected plants but to a lesser extent, showing a detectable difference when compared to the mock-infected plants (Figure 6A). To quantify the amount of YFP-GAI protein that was accumulated in the nuclei of $N$. benthamiana cells, the YFPGAI fluorescence intensity of twenty random nuclei from five different plants for each treatment were analyzed using the ImageJ Software (for more detail see
Methods section). The intensity of YFP-GAI fluorescence accumulated in nuclei of cells of TMV-Cg infected plants was not statistically different from the intensity of YFP-GAI fluorescence detected in nuclei of cells of mock-inoculated plants. However, it was observed a statistically significant reduction of intensity of YFP-GAI fluorescence in nuclei of mock-inoculated plants treated with GA, compared to the YFP-GAI fluoerescence accumulation in nuclei of cells of mock-inoculated plants, previously to the GA treatment (Figure 6B). As is shown in Additional file 7, the amount of nuclei in which YFPGAI protein was detected and the YFP-GAI fluorescence level, were reduced in mock-inoculated plants treated with GA (Additional file 7B). Alternatively, when TMVCg infected plants were treated with GA, the YFP-GAI accumulation detected in nuclei was not significantly reduced compared to the YFP-GAI accumulation detected in the nuclei of infected plants previous to GA treatment (Figure 6B and Additional file 7D). Thus, these results

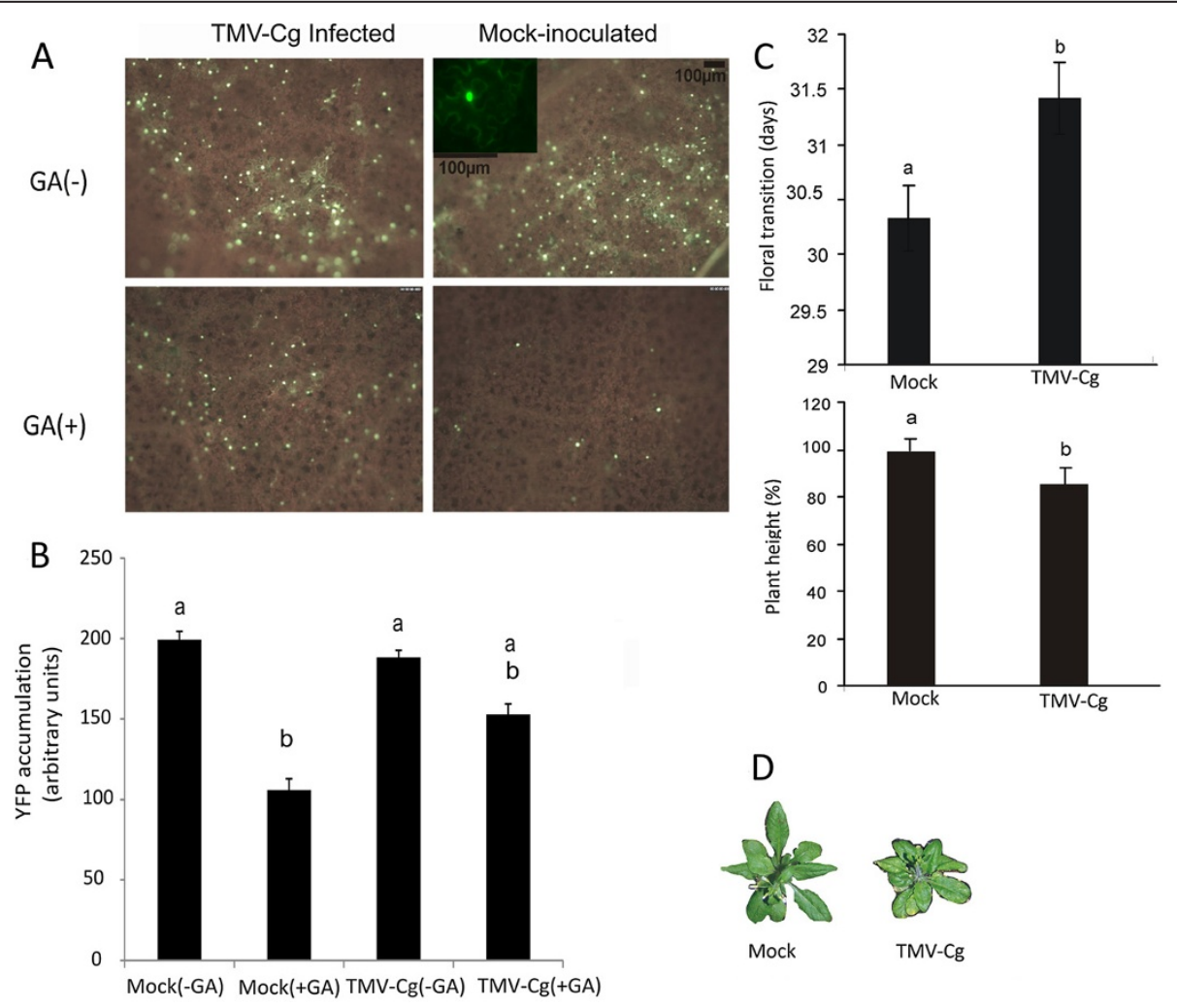

Figure 6 DELLA proteins are stabilized during TMV-Cg infection and reduce plant growth and delay the timing of floral transition. A) Accumulation of YFP-GAI in the nucleus observed using fluorescence microscope. TMV-Cg infected $N$. benthamiana leaves and mock-inoculated $N$. benthamiana leaves were agroinfiltrated with a construction carrying YFP-GAl at $6 \mathrm{dpi}$. At $72 \mathrm{~h}$ post-agroinfiltration leaves were sprayed with $100 \mathrm{uMGA}_{3}(\mathrm{GA}+)$ or water (GA-) and subsequently observed an hour later. This experiment was repeated twice with similar results. B) The bar graph shows the levels of accumulation of YFP present in the nuclei of N. benthamiana cells. Quantitative analysis was performed as is explained in Methods. C) The third true leave of non-transgenic Col-0 (grown to stage 1.08) plants were inoculated with TMV-Cg virus. The floral transition and plant growth (plant height at six weeks) were determined in TMV-Cg infected plants as compared to mock-inoculated plants. D) Representative 6-week-old mockinoculated non- transgenic Col-0 plants and infected non-transgenic Col-0 plants. B) and C) Different letters above the bars represent the significant differences among samples, $p$-values $\leq 0.05$. 
clearly indicate that TMV-Cg virus delays GA-mediated DELLAs degradation.

Furthermore, we analyzed the symptoms produced during TMV-Cg virus infection in Arabidopsis thaliana plants. In concordance with the stabilization of DELLA proteins observed in $N$. benthamiana during TMV-Cg infection, Arabidopsis plants infected with TMV-Cg virus display a reduction in height and a delay in floral transition (Figure 6C and D).

\section{DELLA proteins modulate transcript profiles during TMV-Cg infection}

The stabilization of the DELLA proteins during TMV$\mathrm{Cg}$ infection led us to hypothesis that these proteins could be involved in the modulation of transcript profile during such infection. Therefore, we characterized the role of the DELLA proteins on the modulation of
DELLA-regulated genes during virus infection. For this purpose, WT Arabidopsis plants were infected with TMV-Cg virus and samples were taken at 5, 7 and 9 days post infection to determine the transcriptional levels of a set of DELLA-regulated genes by RT-qPCR. As shown in Figure 7A, WRKY25, WRKY33, MPK3 transcript levels were increased (almost two folds or more) in the TMV-Cg infected WT plants compared to the mockinoculated WT plants at 5 dpi. However, at $7 \mathrm{dpi}$ no differences of expression for these transcripts were detected between the infected and mock-inoculated plants (Figure 7A). At $9 \mathrm{dpi}$, the level of those transcripts was reduced in the infected WT plants compared to the mock -inoculated WT plants (Figure 7A). The expression level of RDR1 did not change in the TMV-Cg infected WT plants with respect to the mock-inoculated WT plants at 5 and $7 \mathrm{dpi}$, but decreased significantly at
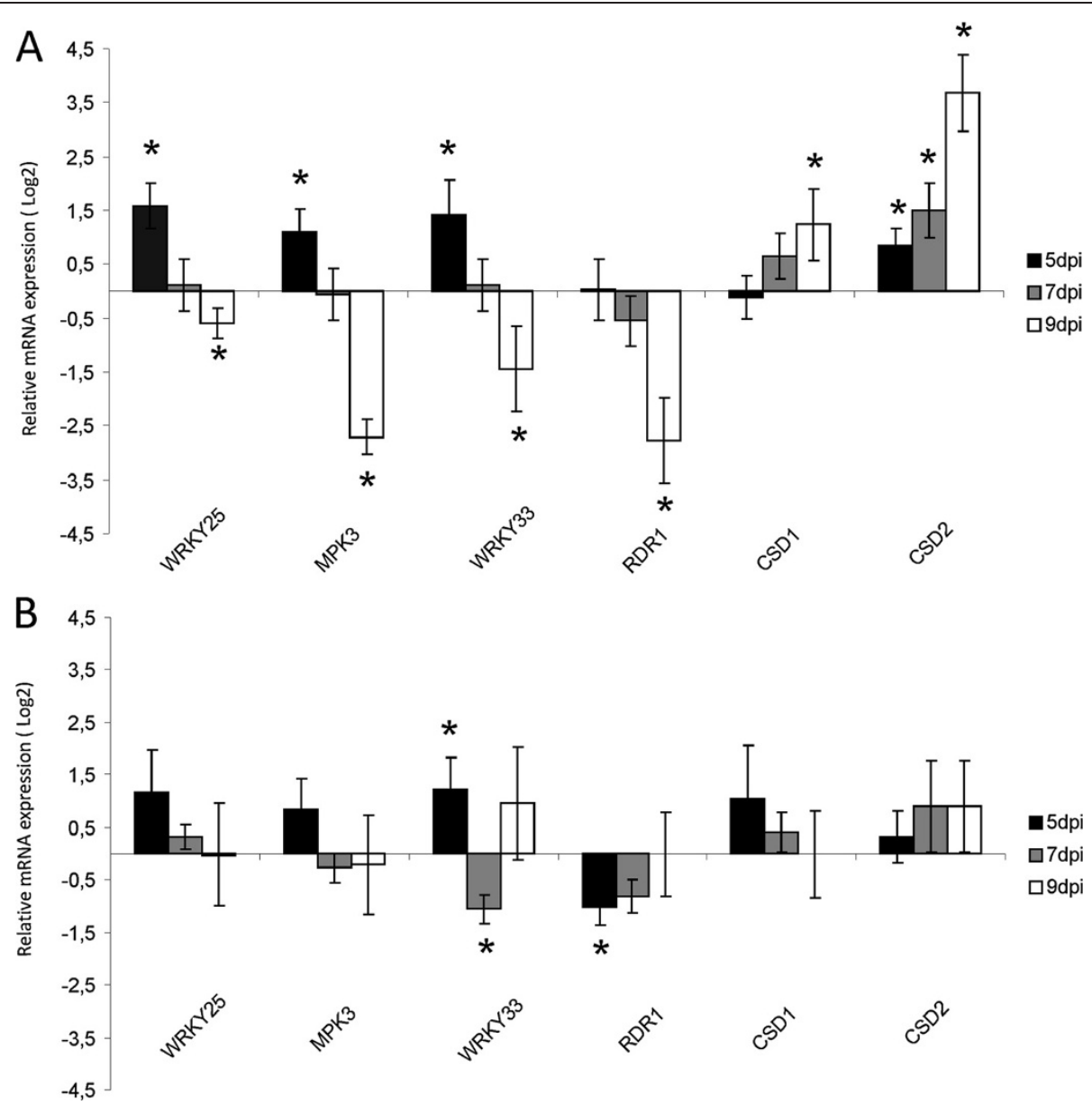

Figure 7 DELLA proteins modulate transcript profiling during TMV-Cg infection. A) Relative mRNA levels of WRKY25, WRKY33, MPK3, RDR1, CSD1, and CSD2 were determined by RT-qPCR in TMV-Cg infected WT-Ler plants compared to mock-infected WT Ler plants at 5, 7 and 9 dpi. Expression level in mock inoculated WT plants was arbitrarily set to one $\left(\log _{2}(1)=0\right)$. B) Expression levels of WRKY25, WRKY33, MPK3, RDR1, CSD1 and CSD2, in quadruple-DELLA mutant infected plants compared to non-infected quadruple-DELLA mutant plants at 5, 7 and 9 dpi. Expression level in mock inoculated quadruple-DELLA plants was arbitrarily set to one $\left(\log _{2}(1)=0\right)$. A) and $\left.B\right)$ The means \pm SE of four biological replicates are shown. This experiment was repeated twice with similar results. 
9 dpi (Figure 7A). The reduced abundance of these transcripts levels at 9 dpi was in agreement with the decreased abundance previously observed during $\mathrm{CgCP}$ transgenic expression.

In parallel, the expression of two other DELLA targets, CSD1 and CSD2, were determined in WT plants at the same point times post infection. CSD1 showed no change at 5 dpi but its abundance was clearly augmented at 7 and 9 dpi. Instead, CSD2 showed a slight increase starting at 5 dpi and a higher increment at 7 and 9 dpi (Figure 7A). Likewise, CSD1 and CSD2 transcript levels were reported to increase by DELLAs stabilization [36]. Therefore, these results show that DELLA-target transcripts are altered during the course of TMV-Cg infection, suggesting that the DELLA proteins may be involved in the defense response to TMV- Cg.

To further study the role of DELLA proteins over the modulation of transcript profile, quadruple-DELLA mutant plants were infected with TMV-Cg virus. WRKY25 and $M P K 3, C S D 1$ and CSD2 transcripts levels were not altered in TMV-Cg infected quadruple-DELLA mutant plants compared to the mock-inoculated quadruple DELLA mutant plants at 5 and $7 \mathrm{dpi}$, while WRKY33 and $R D R 1$ altered their transcriptional levels at 5 and 7 dpi (Figure 7B). Contrary to what was observed in WT plants, none of the genes under studied alters its expression at $9 \mathrm{dpi}$ in the TMV-Cg infected quadruple-DELLA plants compared to the non-infected quadruple DELLA mutant plants (Figure 7B). These results show that DELLA proteins are involved in the modulation of transcript profile during TMV-Cg infection.

\section{DELLA protein stabilization attenuates the defense response to $\mathrm{TMV}-\mathrm{Cg}$ infection}

To determine whether the role of DELLA proteins on SA-mediated pathway has any effect on TMV-Cg infection level, we analyzed the level of $\mathrm{CP}$ accumulation in quadruple-DELLA and gai-1 mutants compared to the $\mathrm{CP}$ accumulation in WT Ler plants. These analyses were performed by RT-qPCR at 5 and $7 \mathrm{dpi}$. A reduced accumulation of TMV-CgCP (more than 100-fold reduction) in the quadruple-DELLA mutants was observed both at 5 and 7 dpi (Figure 8). However, no differences were detected in CP accumulation between the gai-1-mutant plants and the WT Ler plants (Figure 8). In addition, we analyzed the replicase transcript accumulation in quadruple-DELLA mutant compared to the non-mutant Ler plants. Similarly, we observed a reduced accumulation of TMV-Cg replicase in quadruple-DELLA mutants compared to the non-mutant Ler plants (Additional file 8). These results suggest that the modulation of defense pathways by DELLA proteins could be responsible for the reduction of viral accumulation in the non-mutant plants versus the quadruple-DELLA mutants.

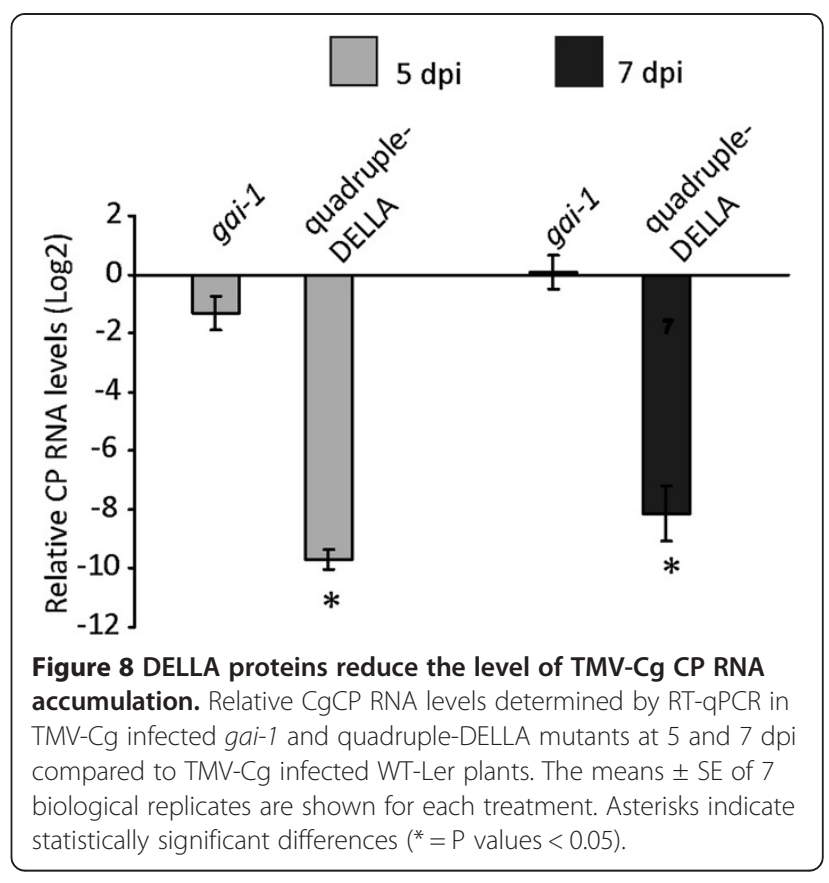

\section{Discussion}

\section{$\mathrm{CgCP}$ downregulates the SA defense response}

Compatible host-virus interactions result in systemic infections that trigger broad changes in gene expression [49]. To study the contribution of $\mathrm{CgCP}$ to the alteration of host gene expression, we employed transgenic plants that express the $\mathrm{CgCP}$ under an inducible promoter. Using this system, we demonstrated that $\mathrm{CgCP}$ reduces the expression of a set of SA-responsive genes (Figure 2A and B). Also, we studied the expression of these genes in a transgenic plant that express the $\mathrm{CgCP}$ under a constitutive promoter. In both transgenic lines we observed a reduction in transcript accumulation of the genes evaluated, with the exception of $A O X 1 A$. While the expression level of $A O X 1 A$ was induced in CP\#72 plants at $24 \mathrm{~h}$ post induction and reduced at $72 \mathrm{~h}$ post induction, it remained unaltered in the $\mathrm{CP} \# 71$ transgenic line, which constitutively expresses CgCP. By contrast, all the other genes behaved similarly in both plant lines. One possible explanation could be that $\mathrm{CgCP}$ only causes a transient modulation of $A O X 1 A$ expression. Alternatively, it could be that the expression level of AOX1A is altered only when $\mathrm{CgCP}$ accumulation reaches higher levels than the observed in the constitutive CP\#71 transgenic line.

$\mathrm{SA}$ induces the expression of SA-responsive genes in CP\#72 plants in the absence of MOF; however, in the presence of MOF, when $\mathrm{CgCP}$ is being expressed, SA fails to induce the expression of these set of genes (Figure $2 \mathrm{C}$ ). These results are in concordance with previous observations made by our group using transgenic tobacco plants that constitutively express TMV CP [19]. 
A previous study that analyzes the ArabidopsisTobamovirus interactions showed that TMV downregulates the expression of SA-signaling components in systemically infected tissues [25]. In the present study, we observed that $\mathrm{CgCP}$ reduces the expression of a set of SA-responsive genes in a context of unchanged SA level. These results suggest that $\mathrm{CgCP}$ may negatively modulate the SA-sensing/signaling pathway by interfering with host components involved in hormone crosstalk. Recently, several studies have shown that plant viral proteins suppress the action of defense signaling components $[25,26]$. In particular, P6 of CaMV acts as a pathogenicity effector and reduces the expression of SAresponsive genes [26]. In fact, P6 modifies NONEXPRESSOR OF PATHOGENESIS-RELATED1 (NPR1) and, as a consequence, reduces the expression of SAresponsive genes, but increases the expression of JAdependent genes. In the present study, no differences were detected in SA or JA accumulation levels in the transgenic plants expressing $\mathrm{CP}$ when compared to the non-transgenic plants (Figure 2D). Therefore, these results suggest that $\mathrm{CgCP}$ suppresses the SA-sensing or downstream signaling pathway by altering one or more components involved in hormone cross-talk.

\section{$\mathrm{CgCP}$ expression stabilizes DELLA proteins and reduces growth of Arabidopsis thaliana}

In recent years, the DELLA proteins have been shown to be involved in modulating cross-talk between hormonal and defense signaling pathways, including the balance of JA and SA signaling [29]. Here, we demonstrated that CgCP delayed the GA-mediated degradation of GFPRGA (a DELLA protein) fusion protein (Figure $4 \mathrm{~B}$ and $\mathrm{C}$ ). Moreover, the expression of DELLA-target genes was increased in plants expressing CgCP. Recently; the impairment of E3 ligases has been suggested to be a strategy employed by viruses to protect proteins that are usually unstable [50]. Furthermore, geminiviral C2/L2 protein has been shown to interact with a component of COP9 signalosome (CSN complex) compromising the CSN activity over CUL1-based SCF ubiquitin E3 ligases [4]. Consequently, CUL-1 based ubiquitin ligases are altered in these plants. These ligases are involved in the regulation of many hormone signaling factors, among which are the DELLA proteins.

Based on these previous data, one possible speculation could be that $\mathrm{CgCP}$ alters some component of the proteasome machinery and, as a result, this would produce a delay in the GA-mediated degradation of DELLA proteins during $\mathrm{CgCP}$ expression. Alternatively, the effect on DELLA stabilization could be explained by the ability of TMV-Cg CP to alter a specific component of the GAsignaling pathway. For example, the P2 protein of RDV interacts with an ent-kaurene oxidase-like protein that is involved in gibberellin biosynthesis and, as a result, infected rice plants show a decrease of gibberellin GA1 levels compared to non-inoculated plants [3]. As a consequence of the reduced levels of GA, rice plants infected with RDV show reduced plant height compared to non-infected plants [3]. Importantly, these findings suggest that the change in GA levels or the alteration of GA-mediated signaling could explain some of the symptoms produced by plant viruses.

Here, we demonstrate that $\mathrm{CgCP}$ expression reduces plant growth both in seedlings and in adult plants when $\mathrm{CgCP}$ transcript levels are accumulated to high levels at early stages of plant development (Figure 3A, 3B, 3D). Taken together, in the present work, we demonstrated that $\mathrm{CgCP}$ stabilizes the DELLA proteins and therefore Arabidopsis exhibits a delay in flowering time as well as a reduction in plant growth.

\section{DELLA proteins negatively modulate antiviral defense signaling pathways}

The role of DELLAs in the modulation of defense response to biotrophic bacterial pathogens has been previously characterized by Navarro et al. [29]. However, their role in viral signaling defense has not yet been studied. This specific area of study is particularly relevant because the SA-signaling components that are involved in antiviral resistance differ from those triggered by other pathogens. For example, the PR proteins are involved in the resistance to bacteria or fungi but do not seem to play a role in antivirus resistance [42]. In addition, the inhibition of viral accumulation by SA seems to be dependent on the action of specific host components. One of these proteins, $R D R 1$, is a component of RNA silencing pathway. $R D R 1$ is needed for the maintenance of basal resistance to several RNA viruses, including TMV [51]. Moreover, the infection of $r d r 1$ mutant plants by TMV-Cg results in higher viral accumulation both in inoculated and in systemically infected leaves [34]. Besides the direct role of RDR1 on viral resistance, this protein may also play an indirect role regulating the expression of other defense-related genes in N. tabacum [52]. Particularly, the expression level of $A O X 1 A$ is increased in WT plants after PVY infection, while the expression level of $A O X 1 A$ is not increased in $r d r 1$ mutants after PVY infection. $A O X 1 A$ has also been proposed to be involved in SA-induced viral resistance in susceptible tobacco plants [21].

In this work, we studied the expression of both $R D R 1$ and $A O X 1 A$ in a quadruple-DELLA mutant and in gai-1 mutant plants. Reduced levels of expression of $A O X 1 A$ and $R D R 1$ genes were observed in the gai-1 mutant plants when compared to the non-mutant Ler plants (Figure 5A). By contrast, the quadruple-DELLA mutants showed higher expression of $A O X 1 A$ and RDR1 than the 
non-mutant Ler plants (Figure 5A). Several reports have shown that reactive oxygen species (ROS) are involved in signaling defense events and potentiate SA signaling [53,54]. Particularly, recent studies have shown that SAinduced RDR1 expression is dependent on NPR1 protein and is enhanced by hydrogen peroxide [55,56]. Furthermore, both SA and hydrogen peroxide are also involved in $A O X 1 A$ induction $[57,58]$. DELLA proteins increases the expression of genes encoding ROS- detoxification enzymes and consequently ROS levels are reduced [36]. Based on these findings, DELLA proteins may be attenuating RDR1 and AOX1A expression by means of changing ROS levels. Moreover, these findings suggest that the stabilization of DELLA proteins during viral infection may be enhancing plants susceptibility to viruses.

\section{TMV-Cg virus stabilizes DELLA proteins and attenuates the} induction of defense signaling during TMV-Cg infection

The DELLA proteins are stabilized during several abiotic and biotic stresses, $[29,59]$ and during viral protein expression [4]. However, the role of DELLA proteins has not been previously described during virus infection. Here, we observed that TMV-Cg virus delayed the GAmediated DELLA degradation in $N$. benthamiana plants (Figure 6A and B). Moreover, we showed that TMV-Cg produced a delay in floral transition and reduced plant height in Arabidopsis thaliana (Figure 6C). This result is in agreement with the involvement of DELLA proteins in the growth inhibition response during stress.

TMV-Cg stabilized DELLA proteins and in turn these proteins negatively modulated the expression of antiviral defense genes. These results led us to hypothesize that DELLA proteins could alter the gene expression profile during TMV-Cg infection. As expected, the expression of the same SA-responsive genes is reduced as TMV-Cg expression progresses (Figure 7A), while an increase of the expression of two DELLA-target transcript, CSD1 and $C S D 2$, is observed (Figure 7A). The expression profile of these genes remained unaltered at $9 \mathrm{dpi}$ in quadrupleDELLA mutants infected with TMV-Cg compared to the non-infected quadruple-DELLA mutants (Figure 7B); which indicates a clear role of DELLA in tested genes alteration. Based on these results, we proposed a model to describe the role of DELLA proteins in the modulation of SA-responsive genes during TMV-Cg infection (Figure 9). As the virus infection progresses, CgCP stabilizes DELLA proteins. This stabilization enhances the expression of SOD-detoxification genes and negatively modulates the expression of SA- responsive genes.

Moreover, based on the results presented here, it can be suggested that $\mathrm{CgCP}$ produces an increasing enhancement of host susceptibility by attenuating the expression of DELLA-regulated SA-responsive defense genes. In agreement with this hypothesis, we observed that infected

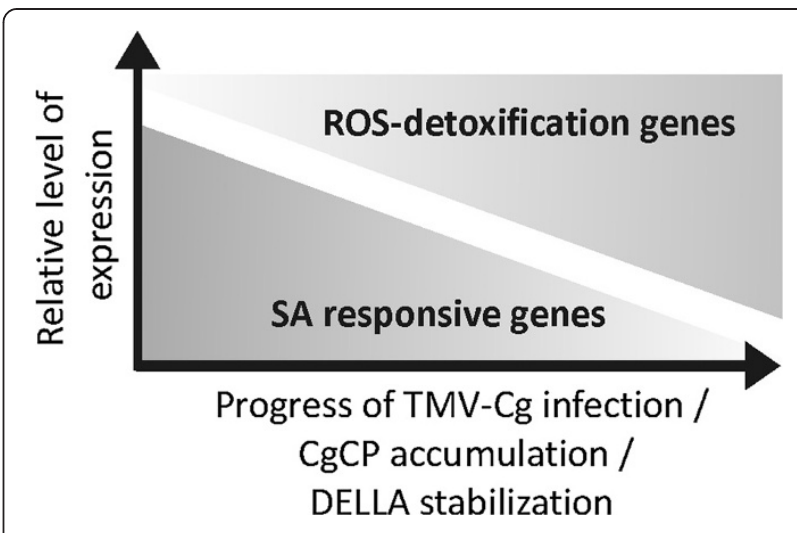

Figure 9 Model proposed to explain the role of DELLA proteins in the modulation of SA-responsive genes during TMV-Cg infection. As the virus infection progresses, CgCP accumulation stabilizes DELLA proteins and SOD-detoxification genes are upregulated. The stabilization of DELLA protein negatively modulates the expression of SA- responsive genes.

quadruple-DELLA mutants (in which defense genes where overexpressed) accumulated approximately 100 -fold less virus CP mRNA than infected WT-Ler plants. However, the level of viral accumulation remained unaltered in infected gai-1 mutants in comparison with infected WT-Ler plants (Figure 8). Similarly, previous observations of other groups have shown that $N a h G$ plants (SA deficient plants) inoculated with a Tobamovirus (ORMV) show no enhanced susceptibility to virus in comparison to WT plants [24]. Huang et al. suggested that viruses could counteract SA-defense responses during compatible interactions [24]. This counteraction therefore could explain why the depletion of SA does not enhance virus susceptibility.

\section{Conclusions}

In summary, the modulation of hormone signaling pathway by plant viral proteins seems to be another mechanism to counteract host defenses. In particular, this work demonstrates that $\mathrm{CgCP}$ attenuates the signaling pathways downstream SA by stabilizing DELLA proteins. Moreover, this research shows that the DELLA proteins are stabilized during virus infections, thus modulating the level of SA antiviral genes. An implication of this is the possibility that the DELLA proteins may enhance the plant susceptibility to TMV-Cg virus infection. Further studies on the role of DELLA proteins during virus infections will add to the understanding of the modulation of SA signaling by Tobamovirus.

\section{Methods}

\section{Plant materials}

The Arabidopsis thaliana lines used in this study were derived either from the Landsberg erecta (Ler) ecotype (pRGA::GFP-RGA, gai-1 (TAIR stock number: CS63) and quadruple-DELLA mutant line) $[60,40]$ or Columbia 
(Col-0) ecotype (CP\#72 transgenic line) [30]. The pRGA:: GFP-RGA x CP\#72 lines were generated by crossing the corresponding lines. Self crosses were performed to obtain homozygous double transgenic plants, confirmed by a genomic polymerase chain reaction (PCR)based screening.

\section{Growth experiments of mature plants}

Arabidopsis thaliana seeds were sown onto pots and stratified at $4^{\circ} \mathrm{C}$ for 3 days to coordinate germination prior to the transference to the AR-95 L Controlled Environmental Chamber (Percival, Perry, IA). Plants were grown under standard conditions. The relative humidity was maintained at 60 to $70 \%$. Plants were watered by subirrigation as needed, usually every two to three days, depending on growth stage. The day length was set to be $16 \mathrm{~h}$ per day. Daytime and nightime temperatures were maintained at 23 and $21^{\circ} \mathrm{C}$, respectively. The average light intensity at the top of the pots was $100 \mu \mathrm{mol} \mathrm{m}{ }^{-2}$ $\mathrm{sec}^{-1}$. To analyze the effect of TMV-Cg CP over growth, the $\mathrm{CP} \# 72$ plants grown to stage 1.08 were treated either with $61.3 \mu \mathrm{M}$ MOF or water. Subsequently, the plant height was measured after six weeks.

\section{Growth experiments of seedlings}

All seeds were surface sterilized and placed on Murashige Skoog (MS) (half-concentrated MS medium) plates at $4^{\circ} \mathrm{C}$ for three days to synchronize germination. The plates were then placed in a growth chamber $\left(20^{\circ} \mathrm{C} ; 16: 8 \mathrm{~h}\right.$ light/ dark photoperiod). Upon completion of germination, the seedlings were treated with $61.3 \mu \mathrm{M}$ MOF or water. The fresh weight of MOF-treated seedlings and mock-treated seedlings was measured 10 days afterwards.

\section{$\mathrm{CgCP}$ induction and SA treatment}

Mature Arabidopsis thaliana plants (1.08 stage) grown in soil were treated (drenched) either with $61.3 \mu \mathrm{M}$ MOF or water $48 \mathrm{~h}$ prior to SA treatments. Then, the plants were sprayed with $0.5 \mathrm{ml}$ of either $0.5 \mathrm{mM}$ salicylic acid (SA) or water. Whole rosettes were sampled $24 \mathrm{~h}$ after SA treatment, immediately frozen in liquid nitrogen and stored at $-80^{\circ} \mathrm{C}$ until RNA isolation.

\section{Detection of GFP-RGA by fluorescence microscopy}

The levels of GFP-RGA were determined by fluorescence confocal microscopy, as previously described [40]. Five-day old $p R G A: G F P-R G A \times C P \# 72$ seedlings were grown on half MS medium, treated with $61.3 \mu \mathrm{M}$ MOF for three days, and subsequently treated for $1 \mathrm{~h}$ with $10 \mu \mathrm{M}$ GA3.

\section{SA and JA Measurements}

The determination of SA and JA contents was performed as previously described [19]. Arabidopsis thaliana Col-0 and CP\#72 leaves were treated with $61.3 \mu \mathrm{M}$ MOF at growth stage 1.08. Then, samples were collected at 0,24 , 48 and $72 \mathrm{~h}$ after MOF treatment.

\section{Nicotiana benthamiana transient expression assays}

The Nicotiana benthamiana plants were inoculated with TMV-Cg virus. The agroinfiltration was performed six days post infection (dpi), as previously described [61]. The GA treatment and YFP-GAI visualization were performed as described by Lozano-Durán [4].

\section{Quantitative analysis of GFP and YFP accumulation}

Twenty random nuclei from five different plants for each treatment were analyzed for the quantification of GFP/ YFP levels (intensity of color) accumulated in Arabidopsis and $\mathrm{N}$. benthamiana cells using the Image Software (http://imagej.nih.gov/ij/). All visible nuclei were quantified, in cases in which the visible nuclei were fewer than twenty. All images were captured using the same microscope settings and processed in the same manner. Statistical comparisons were performed by one-way ANOVA with Tukey post-test using Infostat statistical software (InfoStat version 2008. Grupo InfoStat. FCA, Universidad Nacional de Cordoba). The significance level for both post-tests was $\alpha=0.05$.

\section{Virus infection assays}

The third expanded leaf of each plant (1.08 stage) was dusted with carborundum. Subsequently, $5 \mu \mathrm{l}$ of semipurified TMV-Cg virus diluted in $20 \mathrm{mM}$ phosphate buffer $(\mathrm{pH} 7)$ were added and the surface of the leaf was gently abraded. The mock-inoculated plants were bufferrubbed. Samples of systemic leaves were taken at 5, 7 and $9 \mathrm{dpi}$. The leaves were frozen in individual tubes in liquid nitrogen and stored at $-80^{\circ} \mathrm{C}$ until RNA extraction.

\section{Quantitative real-time polymerase chain reaction (RT-qPCR)} Total RNA was isolated from frozen Arabidopsis thaliana leaf tissues using Trizol Reagent (Invitrogen) and subsequently treated with DNAse I (Invitrogen). For messenger-RNA detection, the first-strand cDNA was synthesized using MMLV (Invitrogen) according to manufacturer's instructions. All RT-qPCR experiments were carried out in an ABI Prism 7500 Real Time PCR System (Applied Biosystems) equipment, the experimental conditions used followed MIQE (Minimun information for publication of quantitative real time PCR experiments) requirements (see Table 1 for more details). Ubiquitin5 (UBQ5, NM-116090) was used as an internal reference gene. The oligonucleotide primer set used for RT- qPCR are listed in Table 2. RT-qPCR data analysis and primer efficiencies were obtained using LinReg PCR software [62]. A reference gene was used to standardize the expression of a given target gene; then, a ratio 
Table 1 Experimental conditions used in RT-qPCR based on MIQE requirements

\section{Experimental design}

Control groups

Treatment groups

\section{Sample}

Type of sample

Procesing procedure

Sample frozen conditions

\section{RNA extraction}

Procedure

Reagents

Details of Dnasa treatment

Contamination assesment

Nucleic acid quantification

Instrument and method

Purity (A260/A280)

RNA integrity

\section{Reverse transcription}

Complete reaction conditions

Amount of RNA and reaction volume

Priming oligonucleotide

Reverse transcriptase

Temp and time

\section{qPCR protocol}

Complete reaction conditions

Reaction volume and amount of CDNA

Primer, Mg and dNTPs concentration

Polymerase

Buffer

Manufacturer of qPCR instrument

\section{qPCR validation}

Specificity

Method of PCR efficiency calculation

\section{Data analysis}

qPCR analysis program

Method of $\mathrm{Cq}$ determination

Outlier identification

Justification of number and choice of reference genes

Description of normalization methods

Number of technical replicates

Statistical method

Software

Repeatability (intraassay variation) $C_{q}$ SD error
CP\#72 water treated plants/mock infected plants

CP\#72 methoxyfenozide treated plants/TMV-Cg infected plants

Arabidopsis leaves

Nitrogen liquid homogenization

$-80^{\circ} \mathrm{C}$

Acid Phenol extraction

TRIzol

DNAsa I Amp Grade, 15 min at room temperature

$<3 \%$

NanoDrop instrument

$>1.8$

Analysed by agarose gel electrophoresis

Reaction was performed as recomendad by Invitrogen ${ }^{\oplus}$

$1 \mu \mathrm{g}$ of RNA, $20 \mu \mathrm{l}$

Oligo $d(T) 20$ primers (Invitrogen ${ }^{\circledast}$ ) and random primers

MMLV® III Reverse Transcriptase

1 hour, $50^{\circ} \mathrm{C}$

$5 \min 95^{\circ} \mathrm{C}$, $\left(30 \operatorname{seg} 95^{\circ} \mathrm{C}, 1 \min 60^{\circ} \mathrm{C}\right) \times 40$ cycles

$20 \mu$ reaction, $20-200$ ng de RNA

3 mM Mg2+, 200nM primers, 0,2 mM de dNTPs

Taq platinum, Invitrogen

20 mM Tris- $\mathrm{HCl}$ (ph 8.4), 50 mM Kcl

ABI 7500, Applied Biosystems

Analysed by agarose gel and melting curve parameters on each qPCR run Mean PCR efficiency per amplicon calculated by LingRegPCR program [62]

LinRegPCR program
LinRegPCR program
LinRegPCR program

3 references genes tested (EF1a, UBQ5, GAPC1) for stability using three stability algorithms. UBQ5 was selected as the reference gene.

Pfaff's mathematical model [63].

3

Permutation test

Fg Satistics

0.8 
Table 2 List of used primers

\begin{tabular}{|c|c|c|}
\hline $\begin{array}{l}\text { Locus/Accesion } \\
\text { number }\end{array}$ & Gene name & Primers sequences \\
\hline \multirow[t]{2}{*}{ At3g22370 } & $A O X 1 A$ & CCGACGATTGGAGGTATGAGATT \\
\hline & & CCGGTGGATTCGTTCTCTGTIT \\
\hline \multirow[t]{2}{*}{ At3g45640 } & MPK3 & TACACGGATITCCGGCGGTGGA \\
\hline & & TCGGAGGACGATACTTAGA \\
\hline \multirow[t]{2}{*}{ At5g26920 } & CBP60g & CGCACCAAGCCGTTGAAACGATG \\
\hline & & CTGGCTCTTGGAGATCCCA \\
\hline \multirow[t]{2}{*}{ At2g38470 } & WRKY33 & GTTCAGTCCCTCTCTIIT \\
\hline & & GTTCTTGTCTCCTTCATTTA \\
\hline \multirow[t]{2}{*}{ At2g30250 } & WRKY25 & ATGTCTTCCACTTCTTTCACC \\
\hline & & GTACCCACCAAAACTCGAC \\
\hline \multirow[t]{2}{*}{ At3g56400 } & WRKY7O & CACCAACGCAGAAACTCCCA \\
\hline & & TTCTCCGTGGACGAACCATG \\
\hline \multirow[t]{2}{*}{ At1g14790 } & $R D R 1$ & TGGAATTGGGATGAGGAAACTG \\
\hline & & TCGTCCTTGCGGAGAATGC \\
\hline \multirow[t]{2}{*}{ At1g08830 } & CSD1 & CCAAAGAGAGACGAAGCA \\
\hline & & GCCTITCTGATCTCAGGA \\
\hline \multirow[t]{2}{*}{ At2g28190 } & CSD2 & GCTCCAGAAGATGAGTGCCGTCA \\
\hline & & CCACCCTITCCGAGGTCATCCTT \\
\hline \multirow[t]{2}{*}{ NM-116090 } & UBQ5 & CGGACCAGCAGCGATTGATT \\
\hline & & ACGGAGGACGAGATGAAGCG \\
\hline \multirow[t]{2}{*}{ At3g63010 } & GID1b & CAGCTTCACTCATTCCTCCGCCA \\
\hline & & GCGTTCCATCCATCGTCGTAAGC \\
\hline \multirow[t]{2}{*}{ At4g36410 } & UBC17 & GGCAAACCAATCCTCCTTCT \\
\hline & & TTGGCGTAAAGAGTTCCTGG \\
\hline \multirow[t]{2}{*}{ At5g50915 } & bHLH137 & TCGAGCTAGAAGAGGCCAAGC \\
\hline & & TCACAGCCCGGAACAAGGT \\
\hline \multirow[t]{2}{*}{ At4g23060 } & IQD22 & TTCCTCATACCCATCGCTACCG \\
\hline & & TCCTCATCCTCCACATCG \\
\hline \multirow[t]{2}{*}{ D38444 } & TMV-Cg replicase & GAAGTTCACTTAGAAGAGTTGC \\
\hline & & AACGGCCTCATCTAACTG \\
\hline \multirow[t]{2}{*}{ D38444 } & TMV-Cg CP & TGTCGCAATCGTATCAAAC \\
\hline & & CTGTATCTGGAAACCGCTG \\
\hline
\end{tabular}

between treatments was calculated using the algorithm developed by Pfaffl et al. [63]. Relative expression ratios and statistical analysis were performed using fgStatistics software interface (J. A. Di Rienzo, personal communications). The cut-off for statistically significant differences was set as $P$ value $<0.05$, indicated as *.

\section{Statistic analysis}

The following variables were analyzed between plant groups: SA and JA levels, plant height, flowering time and fresh weight. All statistical comparisons were performed by one-way ANOVA with Tukey post-test using
Infostat statistical software (InfoStat version 2008. Grupo InfoStat. FCA, Universidad Nacional de Cordoba). The significance level for all post-tests was $\alpha=0.05$.

\section{Additional files}

\begin{abstract}
Additional file 1: Expression of WRKY70, RDR1 and AOX1A in nontransgenic MOF treated Col-0 plants compared to the expression levels in non- transgenic water treated Col-0 plants. Description of the data: The samples were collected at $48 \mathrm{~h}$ after MOF treatment. The expression level in non- transgenic water treated Col-0 plants was arbitrarily set to one $\left(\log _{2}(1)=0\right)$. Asterisks indicate statistically significant differences $\left({ }^{*}=P\right.$ values $\left.<0.05\right)$.
\end{abstract}

Additional file 2: $\mathrm{CgCP}$ expression reduces plant growth and delays the timing of floral transition in CP\#71 transgenic line. Description of the data: Representative WT Col-0 and CP\#71 transgenic 6-week-old plants. Measurements were taken in CP\#71 and WT Col-0 plants. A) Bar graph showing plant height (6-weeks-old) and B) floral transition (number of days to first flower). Each column represents the mean of 25 plants \pm SE.

Additional file 3: Representative Col-0 seedlings of 10 days of age grown for seven days in presence of MOF (MOF) or water (-).

Additional file 4: Expression of DELLA targets genes in quadrupleDELLA and gai-1 adult plants. Relative mRNA levels of individual genes in quadruple-DELLA mutant plants and gai-1 mutant plants were calculated in comparison to WT-Ler plants. Description of the data: Expression level in WT-Ler plants was arbitrarily set to one $\left(\log _{2}(1)=0\right)$. The means of four replicates of quantitative $R T-q P C R \pm S E$ are shown. Asterisks indicate statistically significant differences $\left({ }^{*}=P\right.$ values $<0.05$ ).

Additional file 5: Representative CP\#72/RGAp::GFP-RGA primary seedling roots observed under fluorescence microscope. Description of the data:A) GFP fluorescence observed in water- treated seedlings; B) GFP fluorescence observed in water- treated seedlings subsequently treated with $10 \mu \mathrm{MGA}_{3}$; C) GFP fluorescence observed in MOF treated seedlings; D) GFP fluorescence observed in MOF-treated seedlings subsequently treated with $10 \mu \mathrm{MGA}_{3}$.

Additional file 6: Expression analysis of a subset of defense genes using Genevestigator. Description of the data: mRNA expression level of WT plants treated with flg22 (WT + flg22) was set to one. Relative mRNA levels of individual genes in gai-1 mutant plants treated with flg22 ( gai-1 + flg22) were compared to WT plants treated with flg22. Color scale corresponds to the degree to which the expression was below the control (WT + flg22).

Additional file 7: Representative $N$. benthamiana leaves observed under fluorescence microscope. Description of the data: A) YFP fluorescence observed in non-infected $\mathrm{N}$ benthamiana leaves; B) YFP fluorescence observed in non-infected $\mathrm{N}$. benthamiana subsequently treated with $100 \mu \mathrm{MGA}_{3}$; C) YFP fluorescence observed in infected $\mathrm{N}$ benthamiana leaves; D) YFP fluorescence observed in infected $\mathrm{N}$ benthamiana leaves treated with $100 \mu \mathrm{MGA}_{3}$.

Additional file 8: DELLA proteins reduce the level of TMV-Cg replicase. Description of the data: Expression level in WT-Col-0 plants was arbitrarily set to one $\left(\log _{2}(1)=0\right)$. The means of four replicates of quantitative $R T-q P C R \pm S E$ are shown. Asterisks indicate statistically significant differences $\left({ }^{*}=P\right.$ values $\left.<0.05\right)$

\section{Abbreviations}

CaMV: Cauliflower mosaic virus; CgCP: TMV-Cg coat protein; CP-MR: Coat protein-mediated resistance; GA: Gibberellic acid; JA: Jasmonic acid; MIQUE: Minimum Information for Publication of Quantitative Real-Time PCR Experiments; MOF: Methoxyfenozide; PR1: Pathogenesis-related; RDV: Rice dwarf virus; RDR1: RNA-dependent RNA polymerase 1; SA: Salicylic acid; TMV: Tobacco mosaic virus; WT: Wild type plants.

\section{Competing interests}

The authors declare that they have no competing interests. 


\section{Authors' contributions}

Conceived and designed the experiments: MCR, SA. Performed the experiments: MCR GC DZ. Analyzed the data: MCR SA. Contributed reagents/ materials/analysis tools: MCR GC DZ CAM. Wrote the paper: MCR SA. Revising the article: MCR GC DZ SA. Both authors read and approved the final manuscript.

\section{Acknowledgments}

The authors would like to thank Dr. Julia Sabio y Garcia for the assistance with English-language editing and Dr. Mariana del Vas for her critical comments on the manuscript. We would like to acknowledge Dr. Veronica Arana for providing the pRGA::GFP-RGA transgenic seeds and quadruple-DELLA mutant. This work was supported by the Instituto Nacional de Tecnología Agropecuaria (INTA) [PE 1131022] and by ANPCyT PICT 2011-939.

Received: 12 March 2014 Accepted: 24 July 2014

Published: 3 August 2014

\section{References}

1. Pallas V, García JA: How do plant viruses induce disease? Interactions and interference with host components. J Gen Virol 2011, 92:2691-2705.

2. Hull R: Matthews' Plant Virology. London: Elseiver Academic Press; 2004

3. Zhu S, Gao F, Cao X, Chen M, Ye G, Wei C, Li Y: The rice dwarf virus P2 protein interacts with ent-kaurene oxidases in vivo, leading to reduced biosynthesis of gibberellins and rice dwarf symptoms. Plant Physio/ 2005 139:1935-1945.

4. Lozano-Durán R, Rosas-Díaz T, Gusmaroli G, Luna AP, Taconnat L, Deng XW, Bejarano ER: Geminiviruses subvert ubiquitination by altering CSNmediated derubylation of SCF E3 ligase complexes and inhibit jasmonate signaling in arabidopsis thaliana. Plant Cell 2011, 23:1014-1032.

5. Dreher K, Callis J: Ubiquitin, hormones and biotic stress in plants. Ann Bot 2007, 99:787-822.

6. Padmanabhan MS, Goregaoker SP, Golem S, Shiferaw H, Culver JN Interaction of the tobacco mosaic virus replicase protein with the Aux/ IAA protein PAP1/IAA26 is associated with disease development. J Virol 2005, 79(4):2549-2558

7. Padmanabhan MS, Shiferaw $H_{1}$, Culver JN: The tobacco mosaic virus replicase protein disrupts the localization and function of interacting Aux/IAA proteins. Mol Plant Microbe In 2006, 19(8):864-873.

8. Chen L, Zhang L, Yu D: Wounding-induced WRKY8 is involved in basal defense in Arabidopsis. Mol Plant Microbe In 2010, 23:558-565.

9. Dawson W: MINIREVIEW tobamovirus-plant interactions. Virology 1992 186:359-367.

10. Beachy RN: Coat-protein-mediated resistance to tobacco mosaic virus: discovery mechanisms and exploitation. Phil Trans R Soc Lond 1999, 354:659-664.

11. Callaway A, Gillock ET, Sit TL, Lommel SA: The multifunctional capsid proteins of plant RNA viruses. Annu Rev Phytopathol 2001, 39:419-460.

12. Hilf ME, Dawson WO: The Tobamovirus capsid protein functions as a hostspecific determinant a long-distance movemente. Virology 1993, 193:106-114

13. Asurmendi S, Berg RH, Koo JC, Beachy RN: Coat protein regulates formation of replication complexes during tobacco mosaic virus infection. Proc Natl Acad Sci U S A 2004, 101:1415-1420.

14. Siddiqui SA, Sarmiento C, Valkonen S, Truve E, Lehto K: Suppression of infectious TMV genomes expressed in young transgenic tobacco plants. Mol Plant Microbe In 2007, 20:1489-1494.

15. Dawson WO, Bubrick P, Grantham GL: Modifications of the tobacco mosaic virus coat protein gene affecting replication, movement, and symptomatology. Phytopatology 1988, 78:783-789.

16. Bazzini AA, Asurmendi S, Hopp HE, Beachy RN: Tobacco mosaic virus (TMV) and potato virus $X(P V X)$ coat proteins confer heterologous interference to PVX and TMV infection, respectively. J Gen Virol 2006, 87:1005-1012.

17. Nelson RS, Abel PP, Beachy RN: Lesions and virus accumulation in inoculated transgenic tobacco plants expressing the coat protein gene of tobacco mosaic virus. Virology 1987, 158:126-132

18. Carr JP, Beachy RN, Klessig DF: Are the PR1 proteins of tobacco involved in genetically engineered resistance to TMV? Virology 1989, 169:470-473

19. Conti G, Rodriguez MC, Manacorda CA, Asurmendi S: Transgenic expression of Tobacco mosaic virus capsid and movement proteins modulate plant basal defense and biotic stress responses in Nicotiana tabacum. Mol Plant Microbe In 2012, 25:1370-1384.
20. Lewsey MG, Carr JP: Effects of DICER-like proteins 2, 3 and 4 on cucumber mosaic virus and tobacco mosaic virus infections in salicylic acid-treated plants. J Gen Virol 2009, 90:3010-3014.

21. Chivasa S, Murphy AM, Naylor M, Carr JP: Salicylic acid interferes with tobacco mosaic virus replication via a novel salicylhydroxamic acidsensitive mechanism. Plant Cell 1997, 9:547-557.

22. Alamillo JM, Saénz P, García JA: Salicylic acid-mediated and RNA-silencing defense mechanisms cooperate in the restriction of systemic spread of plum pox virus in tobacco. Plant J 2006, 48:217-227.

23. Whitham SA, Quan S, Chang H, Cooper B, Estes B, Zhu T, Wang X, Hou Y: Diverse RNA viruses elicit the expression of common sets of genes in susceptible Arabidopsis thaliana plants. Plant J 2003, 33:271-283.

24. Huang Z, Yeakley JM, Garcia EW, Holdridge JD, Fan J, Whitham SA: Salicylic acid-dependent expression of host genes in compatible Arabidopsisvirus interactions. Plant Physiol 2005, 137:1147-1159.

25. Wang $X$, Goregaoker SP, Culver JN: Interaction of the Tobacco mosaic virus replicase protein with a NAC domain transcription factor is associated with the suppression of systemic host defenses. J Virol 2009, 83:9720-9730.

26. Love AJ, Geri C, Laird J, Carr C, Yun B-W, Loake GJ, Tada Y, Sadanandom A, Milner JJ: Cauliflower mosaic virus protein P6 inhibits signaling responses to salicylic acid and regulates innate immunity. PLOS ONE 2012, 7:e47535.

27. Sun T-P, Gubler F: Molecular mechanism of gibberellin signaling in plants. Annu Rev Plant Biol 2004, 55:197-223.

28. Grant MR, Jones JDG: Hormone (dis)harmony moulds plant health and disease. Science 2009, 324:750-752.

29. Navarro L, Bari R, Achard P, Lisón P, Nemri A, Harberd NP, Jones JDG: DELLAs control plant immune responses by modulating the balance of jasmonic acid and salicylic acid signaling. Curr Biol 2008, 18:650-655.

30. Yamanaka T, Komatani H, Meshi T, Naito S, Ishikawa M, Ohno T: Complete nucleotide sequence of the genomic RNA of tobacco mosaic virus strain Cg. Virus Genes 1998, 16:173-176

31. Koo JC, Asurmendi S, Bick J, Woodford-Thomas T, Beachy RN: Ecdysone agonistinducible expression of a coat protein gene from tobacco mosaic virus confers viral resistance in transgenic Arabidopsis. Plant J 2004, 37:439-448.

32. Martínez-Andújar C, Ordiz Ml, Huang Z, Nonogaki M, Beachy RN, Nonogaki $\mathrm{H}$ : Induction of 9-cis-epoxycarotenoid dioxygenase in Arabidopsis thaliana seeds enhances seed dormancy. Proc Natl Acad Sci U S A 2011, 108:17225-17229.

33. Boyes DC, Zayed AM, Ascenzi R, McCaskill AJ, Hoffman NE, Davis KR, Görlach J: Growth stage-based phenotypic analysis of Arabidopsis: a model for high throughput functional genomics in plants. Plant Cell 2001, 13:1499-1510.

34. Yu D, Fan B, MacFarlane SA, Chen Z: Analysis of the involvement of an inducible Arabidopsis RNA-dependent RNA polymerase in antiviral defense. Mol Plant Microbe In 2003, 16:206-216.

35. Li J, Brader G, Kariola T, Palva ET: WRKY70 modulates the selection of signaling pathways in plant defense. Plant J 2006, 46:477-491.

36. Achard P, Renou J-P, Berthomé R, Harberd NP, Genschik P: Plant DELLAs restrain growth and promote survival of adversity by reducing the levels of reactive oxygen species. Curr Biol 2008, 18:656-660.

37. Claeys H, De Bodt S, Inzé D: Gibberellins and DELLAs: central nodes in growth regulatory networks. Trends Plant Sci 2014, 19(4):231-239.

38. Zentella R, Zhang Z-L, Park M, Thomas SG, Endo A, Murase K, Fleet CM, Jikumaru Y, Nambara E, Kamiya Y, Sun T-P: Global analysis of della direct targets in early gibberellin signaling in Arabidopsis. Plant Cell 2007, 19:3037-3057.

39. Peng J, Carol P, Richards DE, King KE, Cowling RJ, Murphy GP, Harberd NP: The Arabidopsis GAI gene defines a signaling pathway that negatively regulates gibberellin responses. Genes Dev 1997, 11:3194-3205.

40. Achard P, Cheng H, De Grauwe L, Decat J, Schoutteten H, Moritz T, Van Der Straeten D, Peng J, Harberd NP: Integration of plant responses to environmentally activated phytohormonal signals. Science 2006, 311:91-94

41. Gilliland A, Singh DP, Hayward JM, Moore CA, Murphy AM, York CJ, Slator Carr JP: Genetic modification of alternative respiration has differential effects on antimycin a-induced versus salicylic acid-induced resistance to tobacco mosaic virus. Plant Physiol 2003, 132:1518-1528.

42. Carr JP, Lewsey MG, Palukaitis P: Signaling in induced resistance. In Natural and Engineered Resistance to Plant Viruses. Edited by Loebestein G, Carr JP. London: Academic Press; 2010:57-121. Maramorosch K, Murphy F and Shatkin A (Series Editors): Advances in Virus Research, vol 75.

43. Zimmermann P, Hirsch-Hoffmann M, Hennig L, Gruissem W: GENEVESTIGATOR. Arabidopsis microarray database and analysis toolbox. Plant Physiol 2004, 136:2621-2632 
44. Zhang Y, Xu S, Ding P, Wang D, Cheng YT, He J, Gao M, Xu F, Li Y, Zhu Z, Li $X$, Zhang $Y$ : Control of salicylic acid synthesis and systemic acquired resistance by two members of a plant-specific family of transcription factors. Proc Natl Acad Sci U S A 2010, 107:18220-18225.

45. Han L, Li G-J, Yang K-Y, Mao G, Wang R, Liu Y, Zhang S: Mitogen-activated protein kinase 3 and 6 regulate Botrytis cinerea-induced ethylene production in Arabidopsis. Plant J 2010, 64:114-127.

46. Lippok B, Birkenbihl RP, Rivory G, Brümmer J, Schmelzer E, Logemann E, Somssich IE: Expression of AtWRKY33 encoding a pathogen- or PAMPresponsive WRKY transcription factor is regulated by a composite DNA motif containing W box elements. Mol Plant Microbe In 2007, 20:420-429.

47. Zheng Z, Mosher SL, Fan B, Klessig DF, Chen Z: Functional analysis of Arabidopsis WRKY25 transcription factor in plant defense against Pseudomonas syringae. BMC Plant Biol 2007, 7:2.

48. Gallego-Bartolomé J, Arana MV, Vandenbussche F, Zádníková P, Minguet EG, Guardiola V, Van Der Straeten D, Benkova E, Alabadí D, Blázquez MA: Hierarchy of hormone action controlling apical hook development in Arabidopsis. Plant J 2011, 67:622-634.

49. Whitham SA, Yang C, Goodin MM: Global impact: elucidating plant responses to viral infection. Mol Plant Microbe In 2006, 19:1207-1215.

50. Alcaide-Loridan C, Jupin I: Ubiquitin and plant viruses, let's play together! Plant Physiol 2012, 160:72-82.

51. Xie Z, Fan B, Chen C, Chen Z: An important role of an inducible RNAdependent RNA polymerase in plant antiviral defense. Proc Natl Acad Sci U S A 2001, 98:6516-6521.

52. Rakhshandehroo F, Takeshita M, Squires J, Palukaitis P: The influence of RNA-dependent RNA polymerase 1 on potato virus $Y$ infection and on other antiviral response genes. Mol Plant Microbe In 2009, 22:1312-1318.

53. Noshi M, Maruta T, Shigeoka S: Relationship between chloroplastic $\mathrm{H} 2 \mathrm{O} 2$ and the salicylic acid response. Plant Signal Behav 2012, 7(8):944-946.

54. Manacorda CA, Mansilla C, Debat HJ, Zavallo D, Sánchez F, Ponz F, Asurmendi S: Salicylic acid determines differential senescence produced by two turnip mosaic virus strains involving reactive oxygen species and early transcriptomic changes. Mol Plant Microbe In 2013, 26(12):1486-1498.

55. Liao Y-W-K, Sun Z-H, Zhou Y-H, Shi K, Li X, Zhang G-Q, Xia X-J, Chen Z-X, Yu $\mathrm{J}-\mathrm{Q}$ : The role of hydrogen peroxide and nitric oxide in the induction of plant-encoded RNA-dependent RNA polymerase 1 in the basal defense against tobacco mosaic virus. PLOS ONE 2013, 8:e76090.

56. Hunter $\sqcup$, Westwood JH, Heath G, Macaulay K, Smith AG, Macfarlane SA, Palukaitis P, Carr JP: Regulation of RNA-dependent RNA polymerase 1 and isochorismate synthase gene expression in Arabidopsis. PLoS ONE 2013, 8(6):e66530.

57. Wagner A: A role for active oxygen species as second messengers in the induction of alternative oxidase gene expression in Petunia hybrida cells. FEBS Lett 1995, 368:339-342.

58. Maxwell DP, Nickels R, Mclntosh L: Evidence of mitochondrial involvement in the transduction of signals required for the induction of genes associated with pathogen attack and senescence. Plant J 2002, 29:269-279.

59. Dubois M, Skirycz A, Claeys H, Maleux K, Dhondt S, De Bodt S, Vanden Bossche R, De Milde L, Yoshizumi T, Matsui M, Inzé D: Ethylene response factor6 Acts as a central regulator of leaf growth under water-limiting conditions in arabidopsis. Plant Physiol 2013, 162:319-332.

60. Dill A, Jung HS, Sun TP: The DELLA motif is essential for gibberellin-induced degradation of RGA. Proc Natl Acad Sci U S A 2001, 98:14162-14167.

61. Bazzini AA, Mongelli VC, Hopp HE, Del Vas M, Asurmendi S: A practical approach to the understanding and teaching of RNA silencing in plants. Electron J Biotech 2007, doi:10.2225/vol10-issue2-fulltext-11.

62. Ramakers C, Ruijter JM, Deprez RHL, Moorman AF: Assumption-free analysis of quantitative real-time polymerase chain reaction (PCR) data. Neurosci Lett 2003, 339:62-66.

63. Pfaffl MW: A new mathematical model for relative quantification in realtime RT-PCR. Nucleic Acids Res 2001, 29:e45.

\section{doi:10.1186/s12870-014-0210-x}

Cite this article as: Rodriguez et al:: TMV-Cg Coat Protein stabilizes DELLA proteins and in turn negatively modulates salicylic acid-mediated defense pathway during Arabidopsis thaliana viral infection. BMC Plant Biology 2014 14:210.

\section{Submit your next manuscript to BioMed Central and take full advantage of:}

- Convenient online submission

- Thorough peer review

- No space constraints or color figure charges

- Immediate publication on acceptance

- Inclusion in PubMed, CAS, Scopus and Google Scholar

- Research which is freely available for redistribution 